\title{
Estudo de novas ocorrências de argilas plásticas (ball clays) do nordeste do Brasil para uso em cerâmicas refratárias
}

\section{(Study of new occurrences of plastic (ball) clays from northeastern Brazil for use in refractory ceramics)}

\author{
J. M. Cartaxo, P. de M. Bastos, L. N. L. Santana, R. R. Menezes, G. A. Neves, H. C. Ferreira \\ Programa de Pós-Graduação em Ciência e Engenharia de Materiais, Unidade Acadêmica de Engenharia de \\ Materiais, Universidade Federal de Campina Grande, Av. Aprígio Veloso, 882, Campina Grande, PB, \\ Brazil 58109-970 \\ julianamelo25@gmail.com,paulos@cstr.ufcg.edu.br,lisiane.navarro@ufcg.edu.br, \\ romualdo.menezes@ufcg.edu.br,gelmires.neves@ufcg.edu.br,heber.ferreira@ufcg.edu.br
}

\begin{abstract}
Resumo
A região nordeste do Brasil possui grandes depósitos de argilas plásticas do tipo ball clay situados geralmente na Formação Barreiras e são usados em cerâmica branca e materiais refratários. Essas argilas são constituídas por caulinitas secundárias e matéria orgânica, sendo muito plásticas e quando submetidas a elevadas temperaturas queimam com cores brancas e ocorrem transformações de fases, principalmente formação de cristais de mulita e cristobalita. Este trabalho tem como objetivo estudar novos jazimentos de argilas plásticas visando utilizá-los na produção de materiais refratários. As argilas foram caracterizadas por difração a laser, difração de raios X (DRX), fluorescência de raios X, refratariedade, análise térmica e microscopia eletrônica de varredura (MEV). Os corpos de prova foram prensados e sinterizados a 1000, 1150, 1250, 1280 e $1400{ }^{\circ} \mathrm{C}$. A caracterização após queima foi realizada por DRX e MEV. Em seguida foram determinadas as propriedades físico-mecânicas: absorção, porosidade e tensão de ruptura à flexão. Os resultados evidenciaram que as argilas apresentaram a formação de cristais de mulita com propriedades físicas, químicas e mineralógicas adequadas para uso em cerâmica refratária.
\end{abstract}

Palavras-chave: matérias-primas, refratário, mulita.

\begin{abstract}
The northeast of Brazil has large deposits of ball clays generally situated in Barreiras Formation and are used in white ceramic and refractory materials. These clays are composed of secondary kaolinite and organic matter, being very plastic and when subjected to elevated temperatures burn with white colors and present phase transformations showing mainly crystals formation of mullite and cristobalite. This work aims to study new deposits of ball clays in order to use them to refractory materials production. The clays were characterized by laser diffraction, X-ray diffraction (XRD), X-ray fluorescence, refractoriness, thermal analysis, and scanning electron microscopy (SEM). The samples were pressed and sintered at 1000, 1150, 1250, 1280 and $1400^{\circ} \mathrm{C}$. The characterization after firing was carried out by XRD and SEM. Then, the physical and mechanical properties - absorption, porosity and flexural strength, were determined. The results showed that the clays presented formation of mullite crystals with physical, chemical and mineralogical properties suitable for use in refractory ceramics.
\end{abstract}

Keywords: raw materials, refractory, mullite.

\section{INTRODUÇÃO}

Argilas plásticas do tipo ball clay são definidas como argilas sedimentares de granulometria fina, com cerca de $80 \%$ em massa de partículas com diâmetro médio abaixo de $2 \mathrm{~mm}$, e elevada plasticidade; são refratárias e após queima apresentam coloração variada de creme-claro a branco. São argilas essencialmente cauliníticas, filossilicato dioctaédrico do tipo 1:1 formado pela superposição de tetraedros de sílica $\left(\mathrm{SiO}_{4}\right)$ e folhas de íons de alumínio octaédricos ordenados de forma hexagonal [1-3], com a fórmula estrutural $\left[\mathrm{Al}_{4}\left(\mathrm{Si}_{4} \mathrm{O}_{10}\right)(\mathrm{OH})_{2}\right]$, com composição química teórica de $46,3 \%$ de $\mathrm{SiO}_{2}, 39,8 \%$ de $\mathrm{Al}_{2} \mathrm{O}_{3}$ e $13,9 \%$ de $\mathrm{H}_{2} \mathrm{O}$ [4]. Quanto aos constituintes mineralógicos, as argilas plásticas contêm, além da caulinita, proporções variadas de illita, mica, sericita e quartzo, com pequenas quantidades de matéria orgânica e outros argilominerais do grupo da esmectita [5]. Essas argilas são também muito utilizadas nas massas cerâmicas triaxiais para fabricação de porcelanato, louça sanitária, louça de mesa e isolantes elétricos $[6,7]$. No caso de materiais refratários, as ball clays são transformadas em chamotas pela queima em temperaturas superiores a $1000{ }^{\circ} \mathrm{C}$. As chamotas com granulometria adequada são conformadas utilizando como agente ligante essas mesmas argilas no estado natural e queimadas em temperaturas da ordem de $1350{ }^{\circ} \mathrm{C}$. Os materiais refratários são utilizados em fornos para processamento em elevadas temperaturas, geralmente superiores a $1000{ }^{\circ} \mathrm{C}$, principalmente em 
materiais avançados, suportes de catalisadores, cerâmicas técnicas e principalmente materiais refratários com destaque para revestimentos de fornos para altas temperaturas, incineradores, reatores, concretos, argamassas, fibras cerâmicas, isolantes térmicos, cadinhos para fundição e peças especiais. São produtos de elevado conteúdo tecnológico com especificações muito rígidas pelo fato de serem usadas em condições extremamente adversas. Nos últimos anos, trabalhos relacionados com essas matériasprimas para diversas aplicações industriais têm sido publicados $[8,9]$.

Durante o tratamento térmico das argilas plásticas ocorrem diferentes reações termoquímicas, que dependem dos argilominerais presentes e dos minerais acessórios, tais como quartzo, mica, feldspato e carbonatos, como também das temperaturas de aquecimento e velocidade de resfriamento. Quando essas argilas são submetidas a temperaturas acima de $1100{ }^{\circ} \mathrm{C}$, normalmente, a microestrutura final contém diferentes formas e tamanhos de cristais de mulita e grãos de quartzo, que são controlados pela fluidez da fase líquida da qual se precipitam. A formação destas fases depende das interações entre os diversos óxidos presentes na composição [10-13]. As transformações de fases que ocorrem na sinterização das argilas plásticas vêm também sendo estudadas por diversos pesquisadores, com destaque os trabalhos de [14-19]. Segundo esses autores, a primeira reação que ocorre é a desidroxilação da caulinita a cerca de $590{ }^{\circ} \mathrm{C}$ e a formação em um curto intervalo de tempo da metacaulinita ordenada $\left(\mathrm{Al}_{2} \mathrm{O}_{3} \cdot 2 \mathrm{SiO}_{2}\right)$. As reações que ocorrem na transformação de fase da metacaulinita em mulita são ocasionadas por fases térmicas mal ordenadas. As fases intermediárias neste processo a cerca de $950{ }^{\circ} \mathrm{C}$ têm sido descritas como fase de tipo espinélio de $\mathrm{Al}$ e $\mathrm{Si}\left(\mathrm{Al}_{2} \mathrm{O}_{3} \cdot \mathrm{SiO}_{2}\right)$, espinélio de $\mathrm{Al}$ $\left(\gamma-\mathrm{Al}_{2} \mathrm{O}_{3}\right)$ e nucleação de mulita. A mulita bem cristalizada foi observada em temperaturas superiores a $1200{ }^{\circ} \mathrm{C}$. A quantidade de sílica na mulita é menor do que na caulinita; neste pressuposto, durante as reações térmicas o excesso da sílica amorfa aparece como sílica $\left(\mathrm{SiO}_{2}\right)$ e, eventualmente, cristaliza como a cristobalita a cerca de $1260{ }^{\circ} \mathrm{C}$, ou dependendo da quantidade de fundentes há formação de fase vítrea. A formação de novas fases cristalinas durante $\mathrm{o}$ aquecimento de argilas torna a estrutura mais coesa e mantém a forma, e a fase líquida preenche os poros, que são cruciais para as propriedades dos produtos finais, em particular para a resistência mecânica [20].

Como pode ser visto, as argilas do tipo ball clay têm grande importância em tecnologia de cerâmica branca e principalmente em materiais refratários. No Brasil, observa-se uma carência de estudos tecnológicos sistemáticos para os novos jazimentos de argilas deste tipo de forma a suprir as necessidades da indústria nacional de materiais cerâmicos. Este trabalho tem como objetivo estudar a obtenção de mulita a partir de argilas plásticas do tipo ball clay dos novos depósitos da região nordeste do Brasil para uso como matérias-primas para produção de cerâmicas refratárias.

\section{MATERIAIS E MÉTODOS}

As amostras de argilas analisadas foram provenientes de novas ocorrências de várias regiões do Estado da Paraíba, que foram denominadas: AM01 (proveniente do município de Galante, PB), AM02 (proveniente do município de Massaranduba, PB), AM03 (proveniente do município Serra Redonda, PB), AM04 (proveniente do município de Junco do Seridó, PB), AM05 (proveniente do município de Juripiranga, PB) e AM 06 (proveniente do município de Pedra Lavrada, PB). As argilas foram beneficiadas em moinho de bolas e posteriormente passadas em peneira ABNT N $^{\circ} 200(0,074 \mathrm{~mm})$ para os ensaios de caracterização. As caracterizações físicas, químicas e mineralógicas das amostras foram realizadas pelos seguintes métodos: análise granulométrica por difração de laser (AG), equipamento 1064 da Cilas, em modo úmido; análise química por fluorescência de raios X (EDX), equipamento 720 da Shimadzu; difração de raios X (DRX), equipamento XRD6000 da Shimadzu, com radiação $\mathrm{K} \alpha$ do $\mathrm{Cu}(40 \mathrm{kV} / 30 \mathrm{~mA})$ e velocidade do goniômetro de $2 \%$ min e passo de $0,02^{\circ}$, na faixa de $2^{\circ}$ a $30^{\circ}$; análise termogravimétrica (ATG) e análise térmica diferencial (ATD, sistema de análises térmicas RB-3000 da BP Engenharia), com taxa de aquecimento de $12,5^{\circ} \mathrm{C} / \mathrm{min}$, temperatura máxima para ambos os casos de $1000^{\circ} \mathrm{C}$ e o padrão utilizado na ATD foi o óxido de alumínio $\left(\mathrm{Al}_{2} \mathrm{O}_{3}\right)$ calcinado; análise por microscopia eletrônica de varredura com espectroscopia por dispersão de energia (MEV-EDS), equipamento SX550 da Shimadzu.

$\mathrm{O}$ valor aproximado do ponto de fusão $\left(\mathrm{em}{ }^{\circ} \mathrm{C}\right)$ das amostras foi calculado a partir da composição química por EDX e a fórmula de Schuen [21], sendo:

$$
\text { Temperatura de fusão }=\frac{360+\mathrm{Al}_{2} \mathrm{O}_{3}-\mathrm{R} 0}{0,228}
$$

onde, $\mathrm{Al}_{2} \mathrm{O}_{3}$ é dada pela razão entre o teor de alumina e a soma de teores de alumina e sílica, e RO é a soma dos teores de outros óxidos (em base calcinada, desconsiderando a fração da perda ao fogo). Os valores de cone pirométrico são adimensionais e cada temperatura de fusão corresponde a um determinado número de cone [21].

As amostras foram passadas em peneira ABNT $\mathrm{N}^{0} 80$ $(0,018 \mathrm{~mm})$ e em seguida conformados corpos de prova, com dimensões de $60 \mathrm{~mm}$ x $20 \mathrm{~mm}$ x $5 \mathrm{~mm}$, por prensagem uniaxial com $20 \mathrm{MPa}$. Após conformação os corpos cerâmicos foram secos em estufa na temperatura de $110^{\circ} \mathrm{C}$ por $24 \mathrm{~h}$. Após secagem, foram sinterizados a 1000, 1150, 1250, 1280 e $1400{ }^{\circ} \mathrm{C}$ com taxa de aquecimento de $2{ }^{\circ} \mathrm{C} / \mathrm{min}$ e patamar de $120 \mathrm{~min}$. Após tratamento térmico foram determinadas as seguintes propriedades: absorção de água, porosidade aparente e resistência mecânica à flexão em três pontos [21] (máquina universal Shimadzu AG-IS-100kN). As propriedades físicas foram determinadas a partir da média de cinco ensaios e cada um dos valores foi determinado com dois algarismos significativos. A caracterização mineralógica após queima 
dos corpos cerâmicos foi realizada por DRX e MEV-EDS.

\section{RESULTADOS E DISCUSSÃO}

A Fig. 1 ilustra as curvas de distribuição granulométrica das amostras de argilas estudadas. As amostras apresentaram diâmetro médio (DM) de partículas de: 3,62 um (AM1);

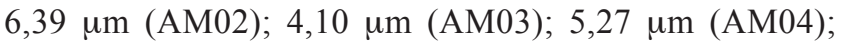
12,12 $\mu \mathrm{m}$ (AM05); e 14,99 um (AM06). Observa-se também que a argila AM01 apresentou para diâmetro $<2 \mathrm{~mm} 43 \%$ de massa acumulada, ou seja, partículas mais finas em relação a argila AM06 que apresentou 18\% de massa acumulada para diâmetro $<2 \mu \mathrm{m}$. Essa é uma característica importante para o tratamento térmico das argilas, pois quanto menor o tamanho de partícula maior a área específica e energia superficial, o que favorece a cinética das reações. Essas diferenças entre argilas plásticas foram observadas em outros trabalhos [2, $22,23]$.

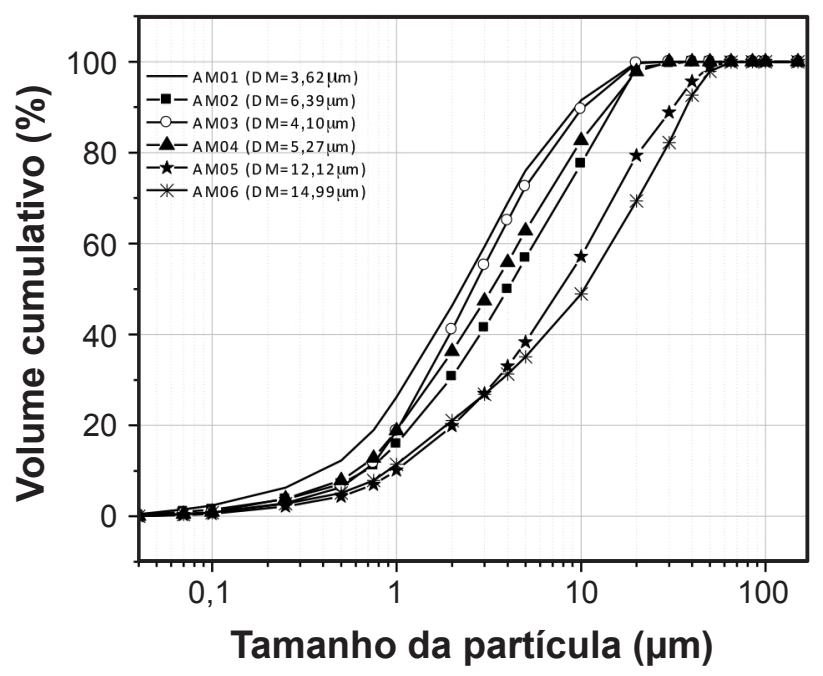

Figura 1: Distribuição de tamanhos de partículas das argilas analisadas.

[Figure1: Particle size distribution of evaluated clays.]
Na Tabela I estão contidos os valores da composição química das argilas determinadas por EDX. As seguintes observações podem ser feitas: $\mathrm{SiO}_{2}(48,98$ a $42,73 \%)$ e $\mathrm{Al}_{2} \mathrm{O}_{3}$ (39,02 a 33,58\%) são os óxidos predominantes; a amostra AM04 apresentou também quantidade apreciável de $\mathrm{Fe}_{2} \mathrm{O}_{3}$ $(3,40 \%)$ e $\mathrm{TiO}_{2}(4,57 \%)$. A relação $\mathrm{Al}_{2} \mathrm{O}_{3} / \mathrm{SiO}_{2}$ variou de 0,87 (AM03) a 0,74 (AM01), valores próximos de 1, indicando maior probabilidade de formação da fase mulita a altas temperaturas (acima de $1000{ }^{\circ} \mathrm{C}$ ), sendo que a maioria das argilas apresentou baixo teor de óxidos fundentes $\left(\mathrm{Na}_{2} \mathrm{O}\right.$ e $\mathrm{K}_{2} \mathrm{O}$ ) sendo um indicativo de alta refratáriedade. Em relação aos teores de $\mathrm{MgO}$, observa-se falta desse óxido nas argilas, sendo um indicativo da ausência de minerais do grupo da clorita [12]. Esses valores foram similares ao encontrados em $[23,24]$.

A partir da composição química (Tabela I) e da fórmula de Shuen (Eq. A), foram calculados os pontos de fusão aproximados das argilas, que estão apresentados na Tabela II; na mesma tabela estão os valores do cone pirométrico (CO) equivalente ou refratáriedade. Analisando os valores do cone pirométrico, observa-se que estes variaram de $\mathrm{CO}$ $32\left(1717^{\circ} \mathrm{C}\right)$ a $\mathrm{CO} 35\left(1781{ }^{\circ} \mathrm{C}\right)$, similares aos obtidos por [2]; essas argilas são consideradas como silicoaluminosas refratárias. Observa-se também que a argila mais refratária foi a AM03 (1781 $\left.{ }^{\circ} \mathrm{C}, \mathrm{CO} 35\right)$; fazendo uma correlação com a composição química, pode-se observar que essa foi a argila que apresentou maior teor de $\mathrm{Al}_{2} \mathrm{O}_{3}$ e ausência de óxidos fundentes. Por outro lado, a argila AM06 foi a de menor cone pirométrico; analisando a composição química, esta amostra apresentou menor relação $\mathrm{Al}_{2} \mathrm{O}_{3} / \mathrm{SiO}_{2}$ e maior teor de óxidos fundentes.

A Fig. 2 ilustra os difratogramas das amostras in natura. Verifica-se similaridade na mineralogia para as seis amostras, com predominância de caulinita $\left(\mathrm{Al}_{2} \mathrm{O}_{3} \cdot 2 \mathrm{SiO}_{2} \cdot 4 \mathrm{H}_{2} \mathrm{O}\right.$, JCPDS 78-2110) e quartzo ( $\mathrm{SiO}_{2}$, JCPDS 46-1045), com exceção da amostra AM02 e AM06 que apresentaram na sua composição ortoclásio. Os dados de EDX (Tabela I) são compatíveis com a composição mineralógica por difração de raios $\mathrm{X}$ (Fig. 2), evidenciando que todos os materiais em análise

Tabela I - Composição química (\% em massa) por EDX das argilas estudadas.

[Table I - Chemical composition (wt\%) by EDX of the studied clays.]

\begin{tabular}{ccccccc}
\hline Óxido & AM01 & AM02 & AM03 & AM04 & AM05 & AM06 \\
\hline $\mathrm{SiO}_{2}$ & 46,12 & 47,42 & 44,90 & 42,73 & 47,08 & 48,98 \\
$\mathrm{Al}_{2} \mathrm{O}_{3}$ & 34,06 & 36,13 & 39,02 & 34,49 & 36,18 & 33,58 \\
$\mathrm{Fe}_{2} \mathrm{O}_{3}$ & 1,98 & ausente & ausente & 3,40 & ausente & ausente \\
$\mathrm{TiO}_{2}$ & ausente & ausente & ausente & 4,57 & ausente & ausente \\
$\mathrm{CaO}$ & ausente & ausente & ausente & ausente & ausente & ausente \\
$\mathrm{Na}_{2} \mathrm{O}$ & ausente & ausente & ausente & ausente & ausente & ausente \\
$\mathrm{K}_{2} \mathrm{O}$ & ausente & 2,03 & ausente & ausente & 1,93 & 5,92 \\
Outros óxidos & 2,63 & 2,61 & 0,75 & 1,51 & 3,00 & 1,51 \\
Perda ao fogo & 15,20 & 11,80 & 15,30 & 13,30 & 11,80 & 10,00 \\
\hline
\end{tabular}


Tabela II - Ponto de fusão aproximado e cone pirométrico equivalente das amostras estudadas.

[Table II - Approximate melting point and pyrometric cone equivalent of the studied samples.]

\begin{tabular}{|c|c|c|}
\hline Amostra & Ponto de fusão $\left({ }^{\circ} \mathrm{C}\right)$ & Cone pirométrico \\
\hline AM01 & 1739 & 34 \\
\hline AM02 & 1734 & 33 \\
\hline AM03 & 1781 & 35 \\
\hline AM04 & 1720 & 32 \\
\hline AM05 & 1743 & 32 \\
\hline AM06 & 1717 & 32 \\
\hline & $c / Q$ & $\begin{array}{l}\text { C - caulinita } \\
\text { Q - quartzo } \\
\text { O - ortoclasio }\end{array}$ \\
\hline $\mathrm{AMO2}=$ & c/a ${ }^{c}$ a & c \\
\hline $\mathrm{AMO}_{3}$ & c/a la & c \\
\hline AM04: & Mianli & c \\
\hline AM05: & c/a ${ }^{c}{ }^{a}$ & c \\
\hline \multirow[t]{3}{*}{ AMO6 } & $\begin{array}{c}\text { c/a co } \\
\text { Mlundurl }\end{array}$ & c \\
\hline & $30 \quad 40$ & 50 \\
\hline & $2 \theta$ (grau) & \\
\hline
\end{tabular}

Figura 2: Difratogramas de raios X das amostras estudadas.

[Figure 2: XRD patterns of the studied samples.]

são silicatos de alumínio com acessórios em quantidades variadas de $\mathrm{K}$ e Fe nas amostras AM01, AM02, AM04, AM05 e AM06. Os padrões de DRX apresentaram picos de difração típicos do mineral caulim, em concordância com outros trabalhos [2, 25].

As curvas de ATD e ATG das argilas estão ilustradas na Fig. 3. Podem-se observar os seguintes picos nas curvas de ATD: pico endotérmico a aproximadamente $110{ }^{\circ} \mathrm{C}$, relacionado à água livre; outro a aproximadamente $588{ }^{\circ} \mathrm{C}$, devido à desidroxilação; e pico exotérmico a aproximadamente 975 ${ }^{\circ} \mathrm{C}$ relacionado à nucleação da mulita. Em relação às curvas de análise térmica gravimétrica (ATG), verifica-se perda de massa total variando de 11,5\% (AM06) a 19,6\% (AM01), relacionada à perda de água, matéria orgânica e hidroxilas. Os valores encontrados estão em concordância com os obtidos em [2, 25].

A Fig. 4 ilustra os difratogramas das amostras de argilas submetidas a $1400^{\circ} \mathrm{C}$. Através da análise dos difratogramas, observa-se que a fase majoritária foi a mulita (JCPDS 791276); também foram encontrados picos característicos da cristobalita (JCPDS 76-0940) e quartzo (JCPDS 46-1045). Esses resultados são similares aos encontrados em [16, 22].

A Fig. 5 ilustra os valores de absorção de água dos
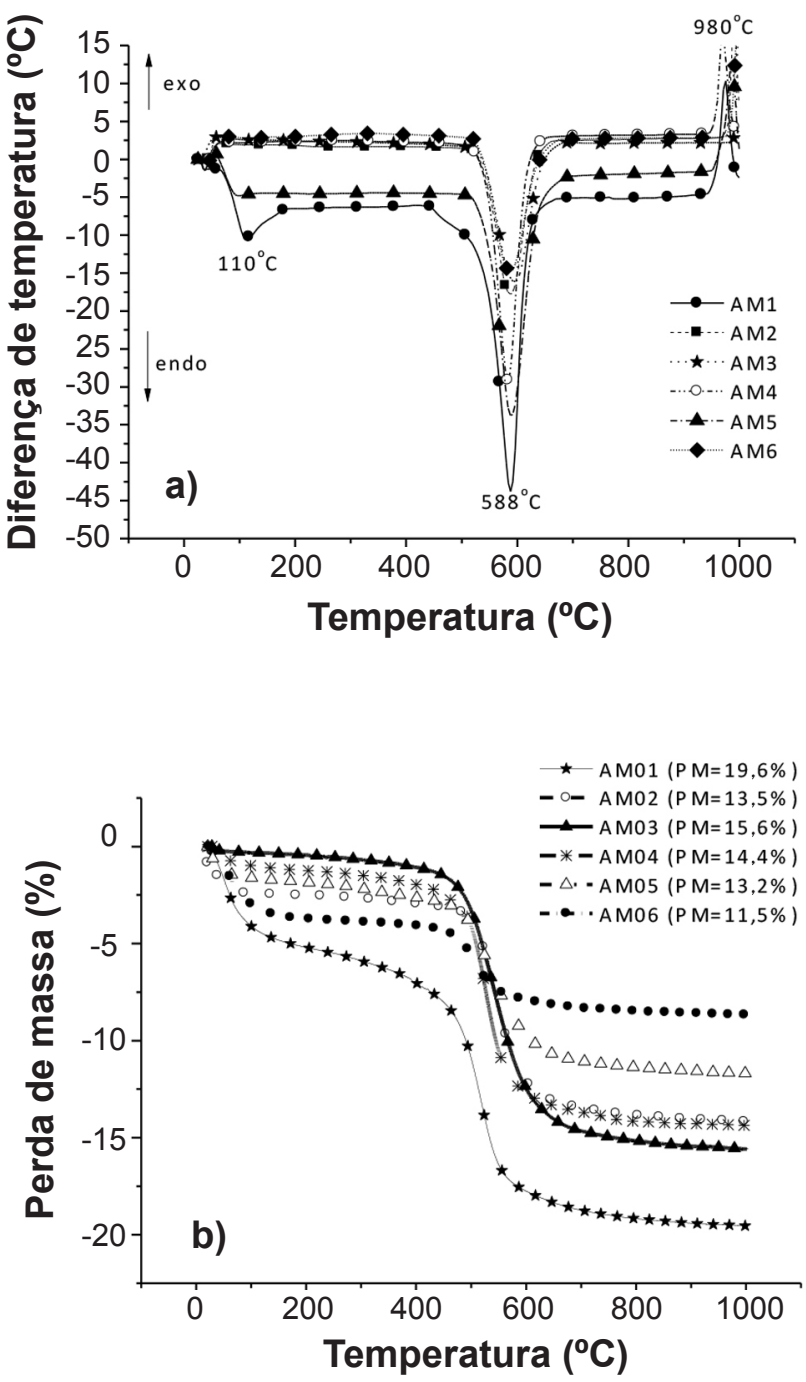

Figura 3: Curvas de ATD (a) e ATG (b) das amostras estudadas. [Figure 3: DTA (a) and TGA (b) curves of the studied samples.]

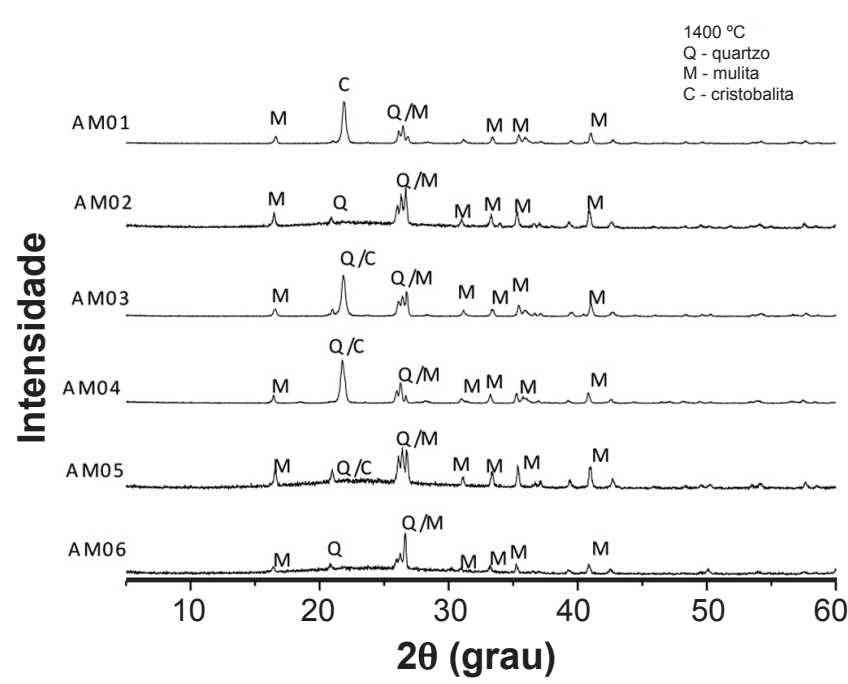

Figura 4: Difratogramas de raios $\mathrm{X}$ das amostras sinterizadas a $1400{ }^{\circ} \mathrm{C}$.

[Figure 4: XRD patterns of the samples sintered at $1400^{\circ} \mathrm{C}$.] 


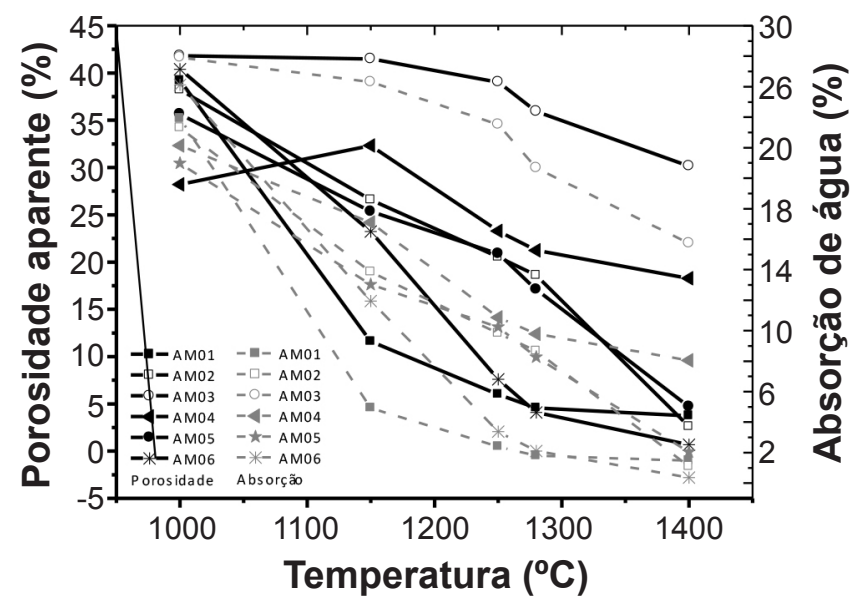

Figura 5: Absorção de água e porosidade aparente das amostras sinterizadas.

[Figure 5: Water absorption and apparent porosity of the sintered samples.]

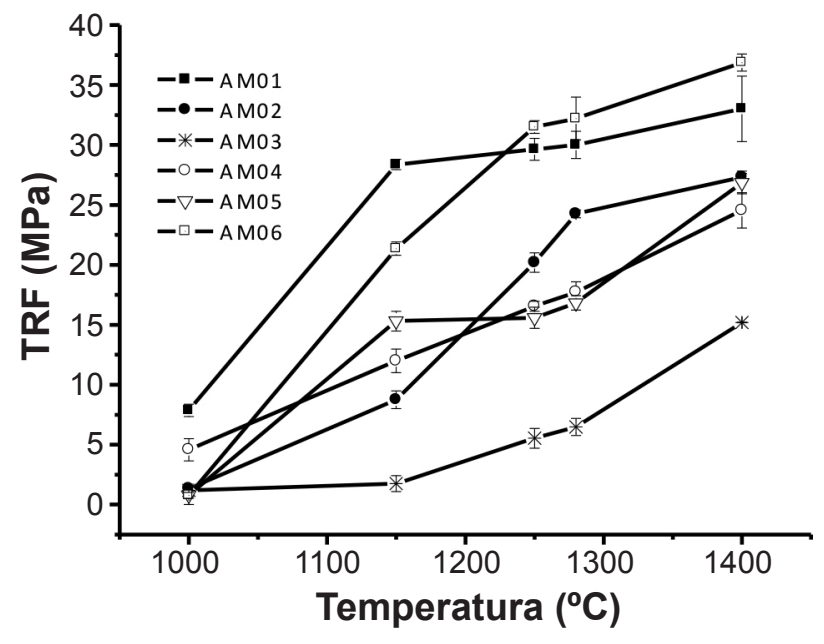

Figura 6: Resistência à flexão (TRF) das amostras sinterizadas. [Figure 6: Flexural strength (TRF) of sintered samples.]
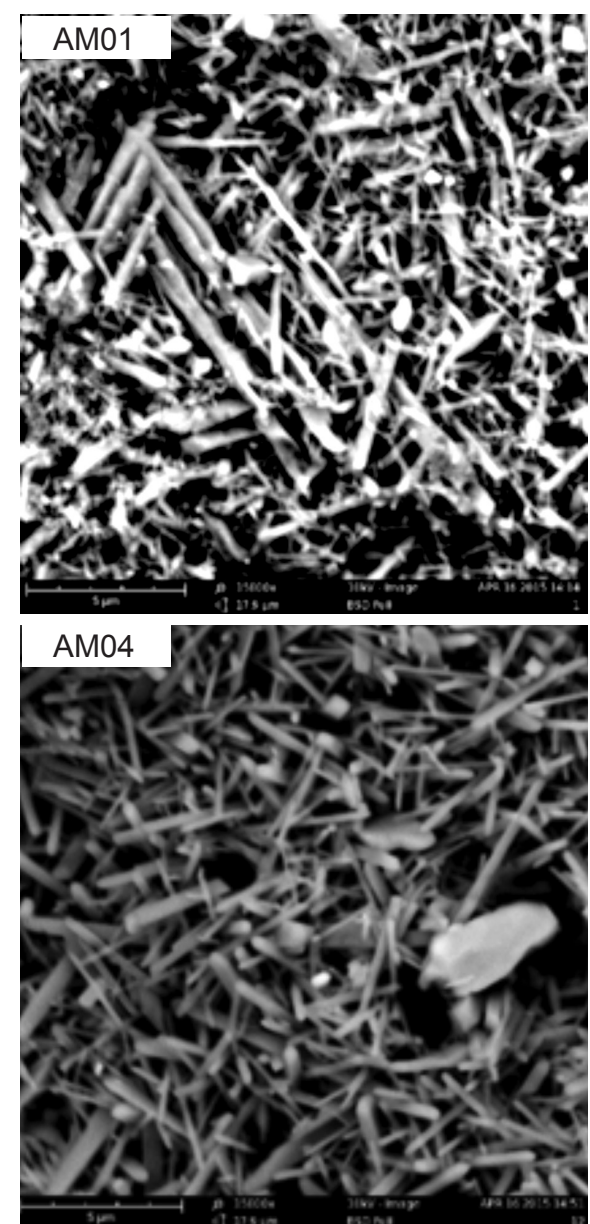
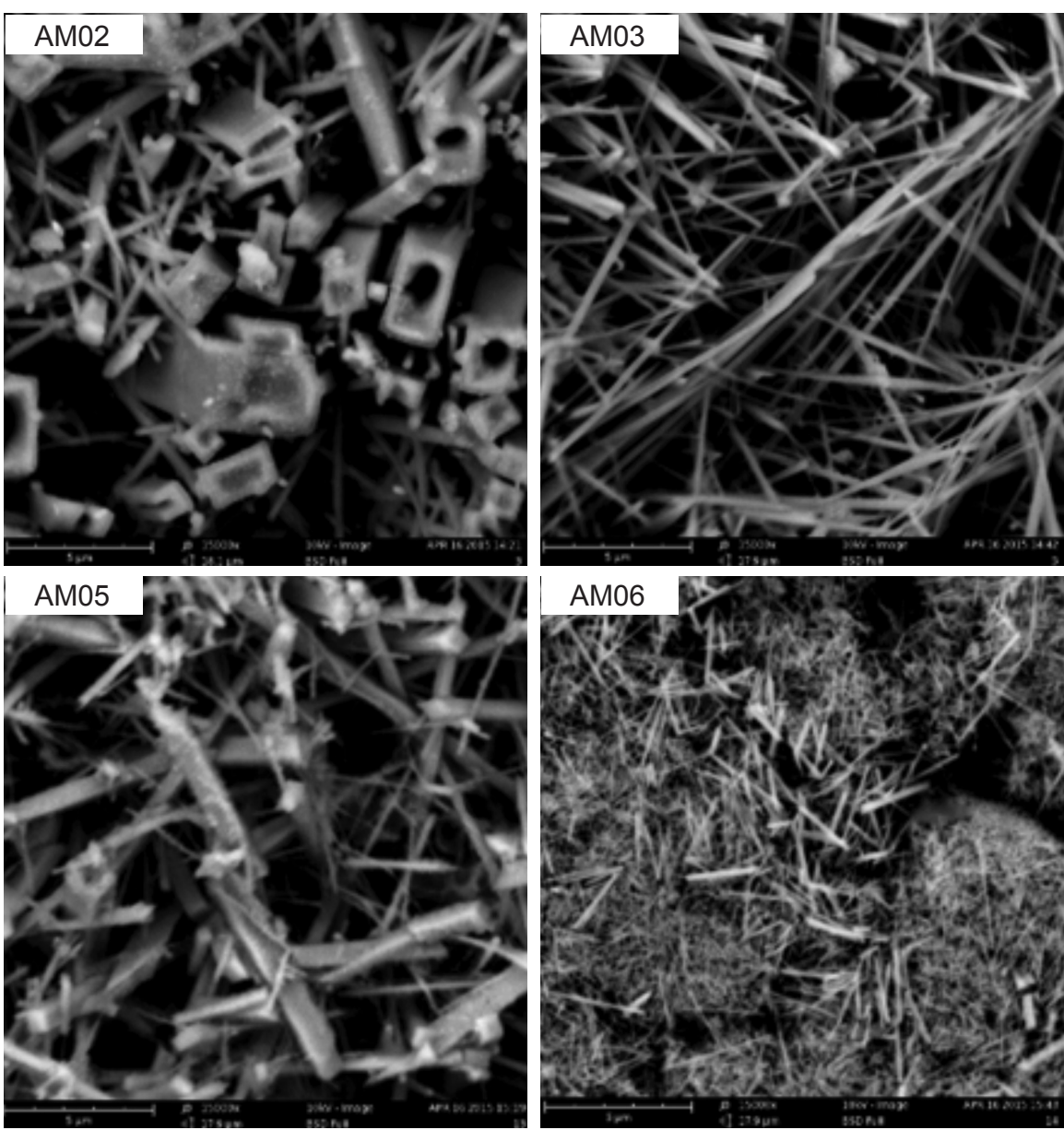

Figura 7: Micrografias obtidas por microscopia eletrônica de varredura das amostras sinterizadas $1400{ }^{\circ} \mathrm{C}$.

[Figure 7: SEM micrographs of the samples sintered at $1400^{\circ} \mathrm{C}$.]

corpos cerâmicos queimados nas temperaturas de 1000 , $1150,1250,1280$ e $1400{ }^{\circ} \mathrm{C}$, com taxa de aquecimento de $2{ }^{\circ} \mathrm{C} / \mathrm{min}$ e patamar de $120 \mathrm{~min}$. Como pode ser observado, as amostras apresentaram redução acentuada da absorção de água com o aumento da temperatura, destacando-se as amostras AM02, AM05 e AM06, o que pode ser justificado pela formação de maior quantidade de fase líquida durante a sinterização, pois estas foram as argilas que apresentaram maiores teores de óxidos fundentes (Tabela I); os fundentes, óxidos alcalinos, principalmente $\mathrm{Na}_{2} \mathrm{O}$ e $\mathrm{K}_{2} \mathrm{O}$, promovem 
a formação da fase líquida [26]. Esses resultados estão de acordo com a faixa de valores reportados na literatura para argilas brancas refratárias [18, 24]. A Fig. 5 também ilustra os valores de porosidade aparente dos corpos cerâmicos queimados. Observando os resultados, verifica-se que os valores de porosidade aberta das peças cerâmicas vão decrescendo (dando lugar a uma porosidade fechada fina) com o aumento da temperatura principalmente acima de $1250{ }^{\circ} \mathrm{C}$; esses resultados corroboram com os de absorção de água e estão de acordo com a faixa de valores reportados na literatura para argilas refratárias [22, 25].

A Fig. 6 ilustra os valores de resistência à flexão dos corpos cerâmicos queimados entre 1000 e $1400{ }^{\circ} \mathrm{C}$. Verifica-se para temperaturas superiores a $1250{ }^{\circ} \mathrm{C}$ valores elevados, sendo o valor máximo de $36,68 \mathrm{MPa}$ para $1400{ }^{\circ} \mathrm{C}$, provavelmente devido à formação da maior quantidade da fase mulita e cristobalita. Os fatores que podem ter favorecido a melhoria na resistência mecânica estão relacionados à redução da porosidade e ao surgimento de novas fases cristalinas como a mulita, pois as características mineralógicas e microestruturais das argilas são afetadas quando são submetidas a aquecimento e novas fases surgem quando altas temperaturas são alcançadas. Alguns trabalhos [27, 28] têm mostrado que a resistência mecânica de peças cerâmicas depende da presença de agulhas de mulita e partículas de quartzo de alta resistência envolvidas pela matriz vítrea, pois essas atuam como inclusões, causando deflexão no trajeto das trincas. Segundo pesquisas $[13,15,19,22,29-31]$, quando se trabalha com síntese de mulita, tem-se observado que o tamanho e entrelaçamento das agulhas de mulita e a acomodação e forma dos cristais são fatores fundamentais que influenciam no comportamento mecânico. O comportamento físicomecânico dessas amostras está compatível com os dados de composição química, mineralógica e refratariedade (cones pirométricos superiores a 32), pois se tratam de silicatos com baixo teor de fundentes, sendo, portanto, adequadas para o uso em cerâmica refratária.

A Fig. 7 apresenta micrografias das amostras após tratamento térmico a $1400^{\circ} \mathrm{C}$. Podem-se observar cristais de mulita com característica acicular, com formato de agulhas, com dimensões variando de aproximadamente $2,74 \mu \mathrm{m}$ (AM05) a 7,65 $\mu \mathrm{m}$ (AM03) e pequenas partículas circulares de quartzo ou cristobalita. Para AM02 observou-se que algumas agulhas apresentaram um aspecto diferenciado, com um furo no seu centro, fenômeno que será posteriormente investigado. De acordo com os resultados de EDS, além de Si e Al, o Fe também estava presente nas agulhas de mulita. Estas observações estão de acordo com os resultados de [22], no qual foi observado que o Fe tende a formar solução sólida na mulita, cuja solubilidade pode ser de até $12 \%$ em massa.

\section{CONCLUSÕES}

A partir dos estudos de caracterização de argilas plásticas da região nordeste do Brasil para uso como matériasprimas cerâmicas para aplicação em refratários, podese concluir que as argilas plásticas apresentaram na sua composição mineralógica caulinita, quartzo e ortoclásio, e elevada refratariedade. Os cristais de mulita formados na sinterização a $1400{ }^{\circ} \mathrm{C}$ das argilas em estudo foram na forma de agulhas e foram observadas poucas quantidades de quartzo e cristobalita; por fim, os resultados evidenciaram seu uso como matérias-primas cerâmicas para aplicação em refratários.

\section{AGRADECIMENTOS}

Os autores agradecem a CAPES (Proc. 2496/2011) e ao CNPq (Proc. 303000/2012-0) pelo apoio financeiro, e ao Laboratórios de Tecnologia de Materiais.

\section{REFERÊNCIAS}

[1] P. Souza Santos, S.P. Toledo, H. Souza Santos, Cerâm. Ind. 14, 1 (2009) 14.

[2] A.C.V. Coelho, P. Souza Santos, Quim. Nova 30, 1 (2007) 146.

[3] A. Baccour, R.D. Sahnoun, J. Bouaziz, Powder Technol. 264 (2014) 477.

[4] A. Tuncuk, S. Ciftlik, A. Akcil, Hydrometallurgy 134135 (2013) 80.

[5] L.S. Wong, R. Hashim, F. Ali, Constr. Build. Mater. 40 (2013) 783.

[6] A. Michot, D.S. Smith, S. Degot, C. Gault, J. Eur. Ceram. Soc. 28 (2008) 2639.

[7] W.P. Gonçalves, V.J. Silva, J. Gomes, R.R. Menezes, G.A. Neves, H.C. Ferreira, L.N.L. Santana, Cerâmica 60 (2014) 316.

[8] C. Belver, J. Bedia, J.J. Rodriguez, Appl. Catal. B 176177 (2015) 278.

[9] H.B. Hadiltaief, M.B. Zina, M.E. Galvez, P. Costa, J. Photochem. Photobiol. A: Chem. 315 (2016) 25.

[10] W.E. Lee, G.P. Souza, C.J. Mcconville, T. Tarvornpanich, Y. Iqbal, J. Eur. Ceram. Soc. 28 (2008) 465.

[11] J. Gomes, J.M. Cartaxo, R.R. Menezes, G.A. Neves, M.I. Brasileiro, L.N.L. Santana, Mater. Sci. Forum 727-728 (2012) 781.

[12] P. Orosco, M.C. Ruiz, J. González, Powder Technol. 267 (2014) 111.

[13] P.C. Yu, Y. W. Tsai, F.S. Yen, W.P. Yang, C.L. Huang, J. Eur. Ceram. Soc. 35 (2015) 673.

[14] A. Khalfaoui, M.A. Hajjaji, Appl. Clay Sci. 45 (2009) 83.

[15] K. Boussois, S. Deniel, N. Tessier-Doyen, D. Chateigner, C. Dublanche-Tixier, P. Blanchart, Ceram. Int. 39 (2013) 5327.

[16] L.N.L. Santana, J. Gomes, G.A. Neves, H.L. Lira, R.R. Menezes, A.M. Segadães, Appl. Clay Sci. 87 (2014) 28.

[17] L.N.L. Santana, J. Gomes, V.J. Silva, W.P. Gonçalves, H.L. Lira, G.A. Neves, R.R. Menezes, Mater. Sci. Forum 820 (2015) 90.

[18] V.J. Silva, G.A. Neves, W.P. Gonçalves, J. Gomes, R.R. Menezes, H.L. Lira, L.N.L. Santana, Mater. Sci. Forum 820 (2015) 84 . 
[19] X. Kong, Y. Tian, Y. Chai, P. Zhao, K. Wang, Z. Li, Ceram. Int. 41 (2015) 4294.

[20] I.K. Oikonomopoulos, M. Perraki, N. Tougiannidis, T. Perraki, H.U. Kasper, M. Gurk, Appl. Clay Sci. 103 (2015) 1.

[21] P. Souza Santos, Ciência e Tecnologia de Argilas, $2^{\mathrm{a}}$ Ed., Edgar Blücher, S. Paulo 1 (1992) 408 p.

[22] W.P. Gonçalves, V.J. Silva, J. Gomes, G.A. Neves, R.R. Menezes, L.N. L. Santana. Mater. Sci. Forum 820 (2015) 46. [23] R.F. Cardoso, H. Souza Santos, P. Souza Santos, Cerâm. Ind. 3, 3 (1998) 47.

[24] J.R. Goes, T.F. Azevedo, T.X.C. Dutra, V.B. Santos, J.B. Severo Junior, L.S. Barreto, Cerâmica 60 (2014) 211.

[25] M.G. Peralta-Sánchez, A.M. Morales-Carrera, A.F.D.C. Varajão, M.M. Ferreira, Cerâmica 57 (2011) 254.
[26] H. Baccour, M. Medhioub, F. Jamoussi, T. Mhiri, J. Mater. Proc. Technol. 209 (2009) 2812.

[27] E. Kamseu, E.C. Leonelli, D.N. Boccaccini, P. Veronesi, P. Miselli, G. Pellacani, U. Chinje Melo, Ceram. Int. 33 (2007) 851.

[28] A. Tucci, L. Esposito, L. Malmusi, E. Rambaldi, J. Eur. Ceram. Soc. 27, 2-3 (2007) 1875.

[29] S. Liu, J. Liu, Y. Zhao, F. Hou, H. Du, Ceram. Int. 40 (2014) 16825.

[30] J. Li, H. Lin, J. Li, J. Wu, J. Eur. Ceram. Soc. 29 (2009) 2929.

[31] M.H. Talou, M.A. Camerucci, J. Eur. Ceram. Soc. 35 (2015) 1021.

(Rec. 21/12/2015, Rev. 04/02/2016, 18/04/2016, Ac. $18 / 04 / 2016)$ 